\title{
The tumor-modulatory effects of Caspase-2 and Pidd1 do not require the scaffold protein Raidd
}

\author{
L Peintner ${ }^{1}$, L Dorstyn ${ }^{2}$, S Kumar ${ }^{2}$, T Aneichyk ${ }^{3}$, A Villunger, ${ }^{*, 1}$ and C Manz| $\left.\right|^{*, 1,4}$
}

The receptor-interacting protein-associated ICH-1/CED-3 homologous protein with a death domain (RAIDD/CRADD) functions as a dual adaptor and is a constituent of different multi-protein complexes implicated in the regulation of inflammation and cell death. Within the PIDDosome complex, RAIDD connects the cell death-related protease, Caspase-2, with the p53-induced protein with a death domain 1 (PIDD1). As such, RAIDD has been implicated in DNA-damage-induced apoptosis as well as in tumorigenesis. As loss of Caspase-2 leads to an acceleration of tumor onset in the E $\mu$-Myc mouse lymphoma model, whereas loss of Pidd1 actually delays onset of this disease, we set out to interrogate the role of Raidd in cancer in more detail. Our data obtained analyzing $E \mu-M y c / R_{\text {Raidd }}{ }^{I-}$ mice indicate that Raidd is unable to protect from c-Myc-driven lymphomagenesis. Similarly, we failed to observe a modulatory effect of Raidd deficiency on DNA-damage-driven cancer. The role of Caspase-2 as a tumor suppressor and that of Pidd1 as a tumor promoter can therefore be uncoupled from their ability to interact with the Raidd scaffold, pointing toward the existence of alternative signaling modules engaging these two proteins in this context.

Cell Death and Differentiation (2015) 22, 1803-1811; doi:10.1038/cdd.2015.31; published online 10 April 2015

A number of mechanisms have evolved to trace and remove potentially dangerous cells. Deregulation of the induction of apoptosis upon oncogenic stress, for example, can facilitate the accumulation of cells prone to undergo malignant transformation. Cell death by apoptosis depends on the cascade-like activation of proteases of the Caspase family. ${ }^{1}$ Among these, the evolutionarily most conserved protease, Caspase-2, turns out to be a potent tumor suppressor in mice $^{2-7}$ and correlative expression data support a conserved role in human cancer. ${ }^{8-13}$

Early studies suggested that Caspase-2 interacts with other proteins for its activation (e.g., after genotoxic stress), but the protease seems also able to auto-activate cell death on its own when present in sufficiently high concentration. ${ }^{14-18}$ The most prominent Caspase-2-containing protein complex was dubbed the 'PIDDosome' and described to contain the p53-induced protein with a death domain (PIDD1) and receptor-interacting protein-associated ICH-1/CED-3 homologous protein with a death domain (RAIDD, also known as CRADD). ${ }^{19}$ Although the molecular details of the pro-apoptotic potential of Caspase-2 are still discussed and alternative roles in the DNA-damage response, cell cycle arrest or sensor of metabolic stress are mechanistically poorly understood, Caspase-2 clearly limits tumorigenesis in different settings. These include aberrant expression of $\mathrm{C}-\mathrm{Myc}$ in $\mathrm{B}$ cells $^{3,4}$ or deletion of the DNAdamage response regulator, ataxia telangiectasia mutated kinase (ATM), both driving lymphomagenesis ${ }^{6}$ as well as overexpression of the Her2/ErbB2 oncogene in breast ${ }^{5}$ or that of mutated KRAS in the lung epithelium, driving carcinoma formation. ${ }^{7}$ One of these studies, addressing also the role of Pidd1 in c-Myc-driven lymphomagenesis, revealed an unexpected oncogenic role for Pidd1, thereby questioning the physiological relevance of the PIDDosome complex in Caspase-2-mediated cell death and tumor suppression. ${ }^{4,20}$ However, the exact role of the scaffold protein Raidd within these processes remains unaddressed so far.

Raidd, a bipartite adapter containing a death domain (DD) and a caspase-recruitment domain (CARD) was first described to bind to the DD-containing kinase RIPK1 and the $C$. elegans caspase CED- $3,{ }^{21}$ supporting a role in cell death initiation. Subsequently, the interaction of Caspase-2 and Raidd was biochemically proven ${ }^{22}$ and proposed to be required for Caspase-2 autoprocessing preceding its activation. ${ }^{19}$ More recent studies propose an antiinflammatory role for Raidd through suppression of nuclear factor kappa-light-chain enhancer (NF-kB) activation and cytokine production upon T-cell receptor stimulation by negatively interfering with the Carma1/Malt1/Bcl-10 signaling complex. ${ }^{23,24}$

First evidence for a potential role of RAIDD in human cancer was discovered in a biochemical screen using mantle cell lymphomas, which detected a downregulation of RAIDD by microarray analysis, ${ }^{10}$ whereas others reported on RAIDD-linked multidrug resistance in osteosarcoma cells. ${ }^{25}$

\footnotetext{
${ }^{1}$ Division of Developmental Immunology, Medical University of Innsbruck, 6020 Innsbruck, Austria; ${ }^{2}$ Centre for Cancer Biology - An Alliance between SA Pathology and the University of South Australia, Adelaide, SA 5001, Australia; ${ }^{3}$ Division of Molecular Pathophysiology, Biocenter, Medical University of Innsbruck, Innsbruck 6020, Austria and ${ }^{4}$ Department of General Pathology, Medical University of Innsbruck, Innsbruck 6020, Austria

${ }^{*}$ Corresponding authors: A Villunger, Division of Developmental Immunology, Medical University of Innsbruck, Biocenter, Innrain 80-82, Innsbruck 6020, Austria. Tel: +43 5129003 70380; Fax: +43 5129003 73960; E-mail: Andreas.Villunger@i-med.ac.at

or C Manzl, Department of General Pathology, Medical University of Innsbruck, Muellerstrasse 44, Innsbruck 6020, Austria. Tel: +43 512900371307 ; Fax: +43 512 9003 73301; E-mail: Claudia.Manz|@i-med.ac.at

Abbreviations: PIDD, p53-induced protein with a death domain; RAIDD, receptor-interacting protein-associated ICH-1/CED-3 homologous protein with a death domain; NF-kB, nuclear factor kappa-light-chain enhancer; MEF, mouse embryonic fibroblast; wt, wild type; 3-MC, 3-methylcholanthrene

Received 16.1.15; revised 20.2.15; accepted 02.3.15; Edited by C Borner; published online 10.4.15
} 
Furthermore, tumor cell apoptosis induced by inhibitors of histone de-acetylases in treatment-resistant adult T-cell leukemia lines reportedly required Caspase-2 and Raidd. ${ }^{26}$ It is also reported that the Caspase-2/Raidd axis is necessary after ER stress, for example, in the course of infection with the oncolytic maraba virus. ${ }^{27}$

Taken together, these studies support a role for RAIDD in drug-induced cancer cell death as well as in tumor suppression, most likely linked to its role as a direct activator of Caspase-2. Alternatively, RAIDD may negatively interfere with PIDD- or BCL10-regulated NF-KB signaling ${ }^{23,24,28}$ and thereby suppress pro-tumorigenic inflammation. To address the role of Raidd in tumorigenesis in more detail, we exploited different mouse models where we induced thymic lymphomas by $\gamma$-irradiation, fibrosarcomas by 3-methylcholanthrene (3-MC) injection or B-cell lymphomas by aberrant expression of the c-Myc proto-oncogene. Our results suggest that Raidd is not a suppressor of tumors in the mouse models tested.

\section{Results}

Loss of Raidd has no impact on tumor formation after DNA damage. As Raidd was reported to have a role in DNAdamage-induced apoptosis because of its ability to form a complex with Pidd1 and Caspase- $2,{ }^{19}$ we used different cancer models to evaluate the impact of Raidd in tumorigenesis induced by DNA lesions. Induction of thymic lymphomas was triggered in 4-week-old mice by repeated low-dose irradiation (1.75 Gy). As reported before, tumor formation was significantly accelerated in $p 53^{+/-}$mice when compared with wild-type (wt) controls, showing a mean survival of 115 and 207 days, respectively. Absence of Raidd, however, had no effect on the onset of tumorigenesis (Figure 1a) or tumor immunophenotype (data not shown) and animals developed thymic lymphomas with a mean survival of 190 days, similar to their wt littermates $(P=0.37)$.

In another tumor model, we treated adult mice with a single injection of 3-MC causing the formation of bulky adducts in DNA leading to fibrosarcoma formation within 6 months. As reported before, ${ }^{29} \mathrm{p5}^{+/-}$mice developed 3-MC-induced sarcomas significantly earlier but loss of Raidd failed to accelerate tumor onset when compared with wt controls (Figure 1b; $P=0.97$ ).

Together with our previously published data ${ }^{4}$ this demonstrates that the PIDDosome, and each of its components individually, are unable to prevent DNA-damage-induced tumor formation inflicted by $\gamma$-irradiation or bulky DNAadduct formation.

c-Myc-induced lymphomagenesis is limited by Caspase-2 in a Raidd-independent manner. Caspase-2 and Pidd1 were reported to modulate lymphomagenesis in E $\mu-M y c$ mice, a model somewhat mimicking human Burkitt lymphoma. ${ }^{4}$ Hence, we introduced Raidd deficiency into E $\mu-M y c$ transgenic animals to explore its impact on tumorigenesis caused by oncogenic stress. Excess proliferation by aberrant c-Myc expression in premalignant mice is usually counterbalanced by increased cell death rates providing a rational why loss of
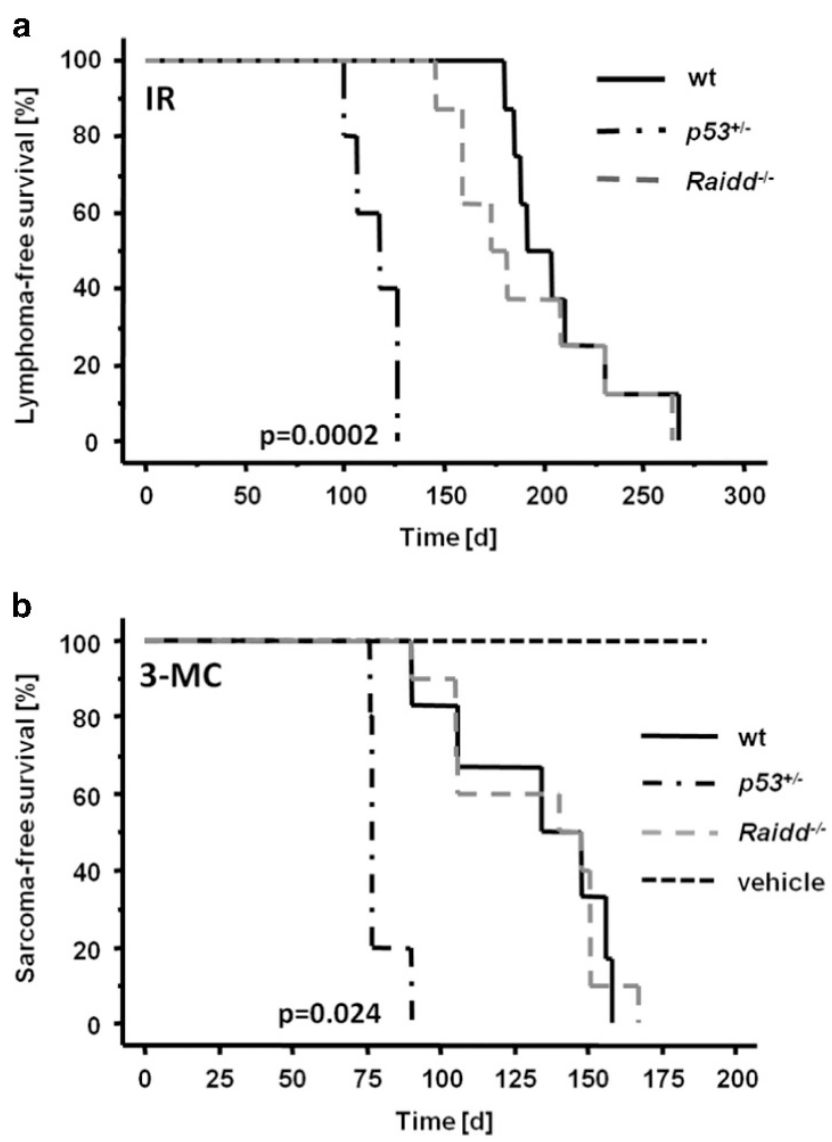

Figure 1 Loss of Raidd does not impact on DNA-damage-induced tumor formation. (a) Kaplan-Meier plot of tumor-free survival in response to repeated lowdose $\gamma$-irradiation $(4 \times 1.75 \mathrm{~Gy})$ of wt $(n=8$, mean $=207$ days $)$, Raidd $^{\prime-}(n=8$, mean $=190$ days $)$ and $p 53^{+/-}$mice $(n=5$, mean $=115$ days $)$. (b) Kaplan-Meier analysis of 3-methylcholanthrene (3-MC)-treated mice. Wild type ( $n=6$, median $=132$ days $) ;$ Raidd $^{-1} \quad(n=10$, mean $=131$ days $) ; p 53^{+/-} \quad(n=5$, mean $=79$ days). Wild-type mice injected with vehicle only $(n=3)$ were used as solvent controls

pro-apoptotic proteins, for example, of the BH3-only group, accelerates disease onset. ${ }^{30-33}$

To evaluate the role of Raidd early in disease development, the B-cell subset composition was assessed in premalignant $\mathrm{E} \mu-\mathrm{Myc} /$ Raidd $^{-/}$mice. In line with published data, ${ }^{4,32,34,35}$ the numbers of $\mathrm{B}^{2} 2 \mathrm{O}^{+} \mathrm{IgM}^{-}$pro/pre- $\mathrm{B}$ cells were increased in bone marrow and spleen, whereas numbers of mature $B$ cells were diminished in the periphery of $E \mu-M y c$ mice when compared with wt controls (Figure 2a). However, no other gross alterations within the B-cell composition and distribution in $E \mu-M y c$ mice specifically lacking Raidd were noted.

To monitor B-cell survival upon oncogenic stress in the absence or presence of Raidd, we next sorted pre-B and immature B cells of premalignant mice and put them in culture. Notably, B cells from non-transgenic Raidd ${ }^{-1}$ mice appeared to be slightly less sensitive to spontaneous cell death when compared with wt (Figure $2 b$ ). As reported before, ${ }^{30-32} \mathrm{~B}$ cells derived from $E \mu-M y c$ mice died more rapidly when compared with the non-transgenic counterparts but additional lack of Raidd had no relevant impact (Figure 2b). Similarly, Raidd deficiency had no impact on homeostatic or c-Myc-driven 

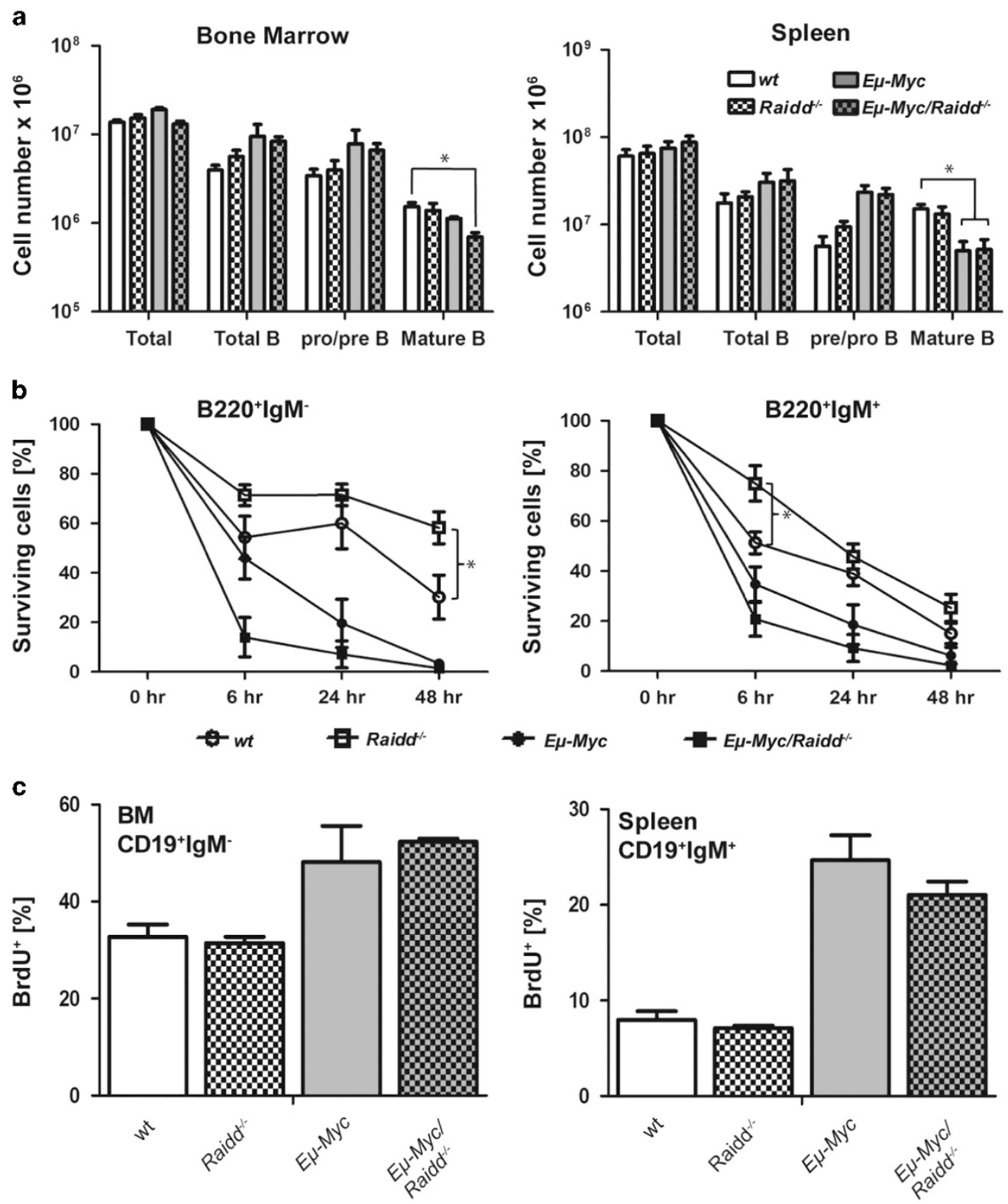

Figure 2 B-cell subset composition, proliferation and cell death responsiveness in premalignant Raidd ${ }^{\prime-}$ - mice. (a) The development and the distribution of B cells in bone marrow and spleen was assessed in 4-week-old $E \mu$-Myc transgenic mice lacking or expressing Raidd. Single-cell suspensions of the organs were counted and stained with cell surface marker-specific antibodies and analyzed by flow cytometry. Bars represent means ( $n=3-5$ per genotype) \pm S.E.M. (b) Sorted premalignant $B$ cells (pre-B from bone marrow, $\mathrm{CD}_{1} 9^{+} \mathrm{IgM}^{-} \mathrm{CD}_{4} 3^{-}$or immature $\mathrm{B}$ cells $\mathrm{CD} 19^{+} \mathrm{IgM}{ }^{\text {low }}$ from spleen) were analyzed for spontaneous death after 6,24 and $48 \mathrm{~h}$ using Annexin-V plus 7-AAD staining in a flow cytometer. Symbols represent means of $n=3-5$ per genotype \pm S.E.M. (c) Proliferation rates were quantified $4 \mathrm{~h}$ after a single injection of BrdU in bone-marrow-derived pro/pre-B cells, $\left(\mathrm{CD}_{19^{+}} \operatorname{lgM} \mathrm{M}^{-}\right)$or $\left(\mathrm{CD}_{1}{ }^{+} \mathrm{IgM}^{+}\right) \mathrm{B}$ cells from spleen. Bars represent means $(n=3-5)$ per genotype \pm S.E.M.

B-cell proliferation, as assessed by BrdU-incorporation analysis in immature $\mathrm{CD}^{1} 9^{+} \mathrm{IgM}^{-}$and $\mathrm{CD}^{-1} 9^{+} \mathrm{IgM}^{+} \mathrm{B}$ cells from bone marrow or spleen of premalignant mice (Figure 2c).

Next, cohorts of E $\mu-M y c, E \mu-M y c /$ Raidd $^{--}$and, for reference, $E \mu-M y c / C a s p-2^{-/}$mice were monitored for tumor onset. Strikingly, although loss of Caspase-2 leads to accelerated disease onset (mean survival: $101 \mathrm{~d}$ ), loss of Raidd had no effect, when compared with Raidd-proficient $E \mu-M y c$ mice presenting with a mean survival: 128 versus 124 days (Figure 3a). White blood cell counts and tumor burden were also comparable between genotypes (Supplementary Figures 1a and b).
Tumors were subsequently classified by flow cytometry as either pre-B cell $\left(\operatorname{lgM}^{-}\right)$, immature $B$ cell $\left(\operatorname{lgM}^{+}\right)$, mixed $\left(\operatorname{lgM}^{+/-}\right)$ or as early hematopoietic progenitor-derived lymphomas $\left(B 220^{+} \mathrm{CD}^{+}\right) \cdot X^{2}$ analysis confirmed differential distribution between wt and Casp- $2^{-1-}$ tumors $(P=0.043)$, as reported before ${ }^{4}$ but no significant difference was noted between wt and Raidd $^{-1-}$ tumors (Figure 3b).

Further, in lymphoma cells derived from E $\mu-M y c /$ Raidd $^{\text {/- }}$ mice, cell cycle distribution (Figures $4 \mathrm{a}$ and b), spontaneous (Figure 4c) and drug-induced cell death (Figure 4d) were monitored and found comparable to their wt counterparts. Notably, Caspase-2-deficient tumors showed again an 


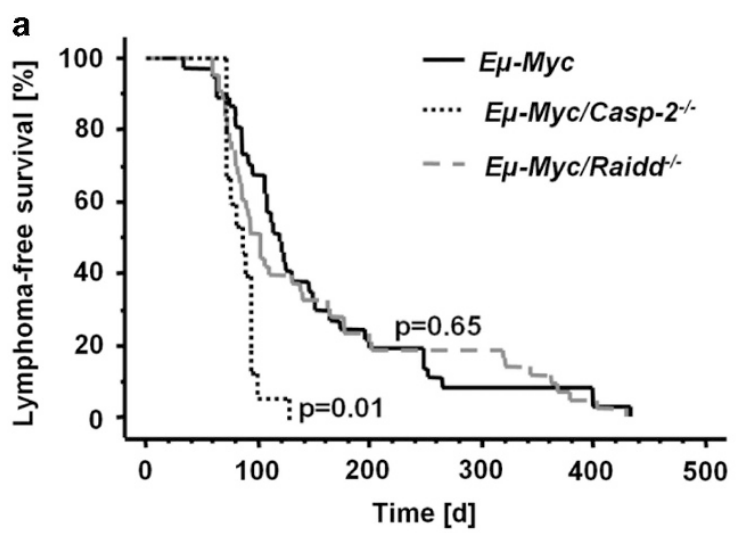

b

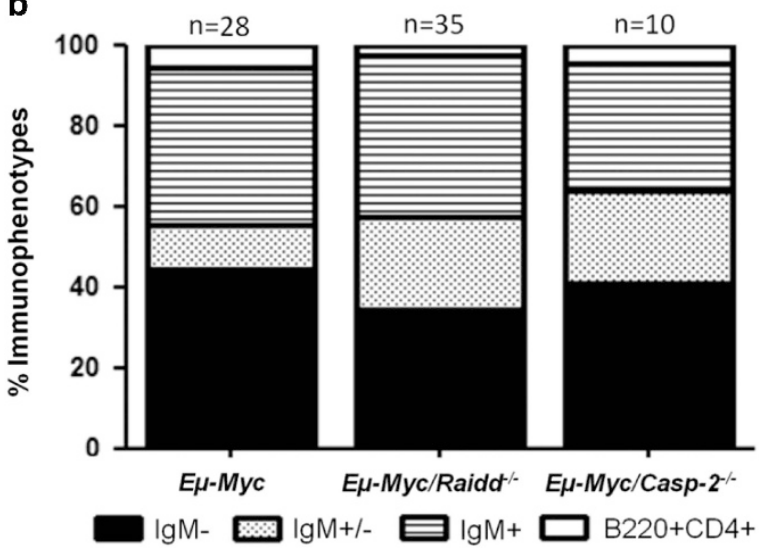

Figure 3 Suppression of c-Myc-induced B-cell lymphoma formation by Caspase2 does not depend on Raidd. (a) Lymphoma-free survival of $E \mu$-Myc $(n=37$, mean $=128$ days $), E \mu-M y c / R^{2}$ aidd ${ }^{\prime-}(n=43$, mean $=124$ days $)$ and $E \mu-M y c /$ Casp- $2^{-1}$ mice $(n=15$, mean $=101$ days). (b) Flow cytometric analysis of tumor immunophenotype. A comparison of the frequency of the different immunophenotype across genotypes by Chi-square test revealed differences between wt and Casp- $2^{-1-}$ tumors $(P=0.043)$, whereas the overall distribution between wt and Raidd $^{/-}$tumors was not significantly different $(P=0.1)$

increase in phospho-Histone $\mathrm{H} 3$ staining, suggesting perturbed cell cycle control (Figure 4b). In line with a lack of impact on tumor latency, loss of Raidd did not release the pressure to inactivate p53, a known secondary hit, usually observed in about $25 \%$ of all $E \mu$-Myc lymphomas. ${ }^{36}$ Inactivation of $\mathrm{p} 53$, as assessed by western blotting for p53 and p19ARF, was seen at similar rates in $E \mu-M y c(26 \%, n=11)$ and $E \mu-M y c /$ Raidd $^{-1-}$ $(27 \%, n=19)$ tumors (Supplementary Figures 1c and d).

Overall, these data demonstrate that the adaptor protein Raidd is not limiting Myc-driven tumorigenesis thereby uncoupling the tumor-suppressor function of Caspase-2 from Raidd-dependent autoactivation and the oncogenic potential of Pidd1 from Raidd-modulated NF- $\kappa$ B signaling.

Loss of Caspase-2 promotes aneuploidy. As Caspase-2 has been implicated in mediating mitotic catastrophe as a response to DNA-damage after failed cell cycle arrest ${ }^{37,38}$ and that $\mathrm{c}-\mathrm{Myc}$ overexpression drives proliferation stress leading to DNA damage, ${ }^{39}$ we investigated if lack of Caspase-2 would influence genomic stability of normal, premalignant or transformed cells.
First, we investigated chromosomal stability in SV40immortalized mouse embryonic fibroblasts (MEFs) from wt and Caspase-2-deficient mice (Figures 5a and b). Numbers of micronuclei, which emerge after errors during mitosis and result in individual chromosomes or fragments outside of the main nucleus, were significantly increased in cells lacking

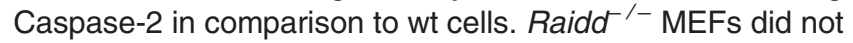
show increased susceptibility to micronuclei formation (Figure 5b). Chromosomal stability was further examined by counting chromosome numbers in metaphase spreads in B-cell lymphomas (Figures $5 c-e$ ). E $\mu-M y c$ transgenic B-cell tumors deficient for Caspase-2 did show a higher variation of chromosome numbers within individual tumor samples. Taken together, these data are consistent with published results, indicating that Caspase-2 acts in maintaining genomic stability. ${ }^{37}$

In an attempt to identify potential effectors of Caspase-2 in this process and based on the reported role of Caspase-2 in p53 activation and target gene expression upon DNA damage, ${ }^{40}$ we performed qPCR analysis as well as unbiased genome-wide expression analysis comparing mRNA from premalignant splenic $\operatorname{lgM}^{+} D^{-} B$ cells of $E \mu-M y c$ transgenic animals deficient or proficient for Caspase-2 or Raidd. We started by comparing expression levels of mRNAs of p21, Noxa and Puma by qRT-PCR, anticipating that c-Myc-driven p53 activation would result in reduced expression of these targets in the absence of Caspase-2. ${ }^{40}$ This, however, was not the case, or at least the noted differences did not reach statistical significant differences (Supplementary Figure 2). Comparison of gene-chip data revealed only few candidates, including Fbxw10, Fgd6, Hist3h2a, Hmha1, Igf1R, Lyrm7, RhoBTB1, Slc25a13 and Zfp39, that were deregulated more than twofold in the absence of Caspase-2 or RAIDD when compared with wt (Supplementary Figure 2). Only one of these candidates, that is, RhoBTB1, was subsequently confirmed by qPCR analysis. However, as RhoBTB1 is unlikely related to genomic stability this was not followed up in detail during the course of this study. This indicates that there are no significant changes, at least in the premalignant $B$ cells analyzed that may contribute to the genomic instability observed following loss of Caspase-2.

\section{Discussion}

In this study, we investigated the relevance of Raidd in tumorigenesis sparked by its function as an adaptor protein for Caspase-2 and Pidd1, both being reported to influence tumorigenesis in vivo. Caspase-2 is well characterized as a tumor-suppressor gene in various mouse cancer models, ${ }^{3-7}$ whereas loss of Pidd1 leads to a delayed tumor onset upon c-Myc overexpression. ${ }^{4}$ Our data demonstrate that loss of Raidd has no influence on the development of radiationinduced thymic lymphomas or chemically induced fibrosarcomas (Figure 1). Although the mean latency in the absence of Raidd appeared to be shortened when compared with wt (190 versus 205 days), statistical significance was not reached, possibly due to the rather small cohort size, requiring more detailed follow up. Yet, these observations are similar to the published results in Caspase-2- and Pidd1-deficient mice ${ }^{4}$ 
a
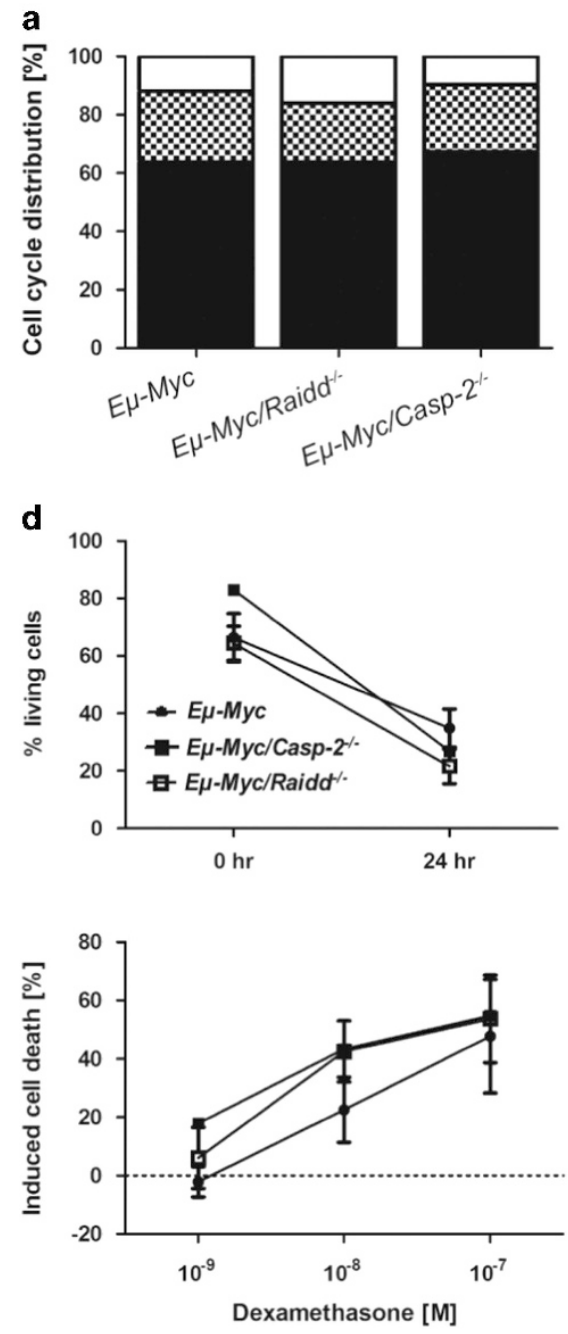

b
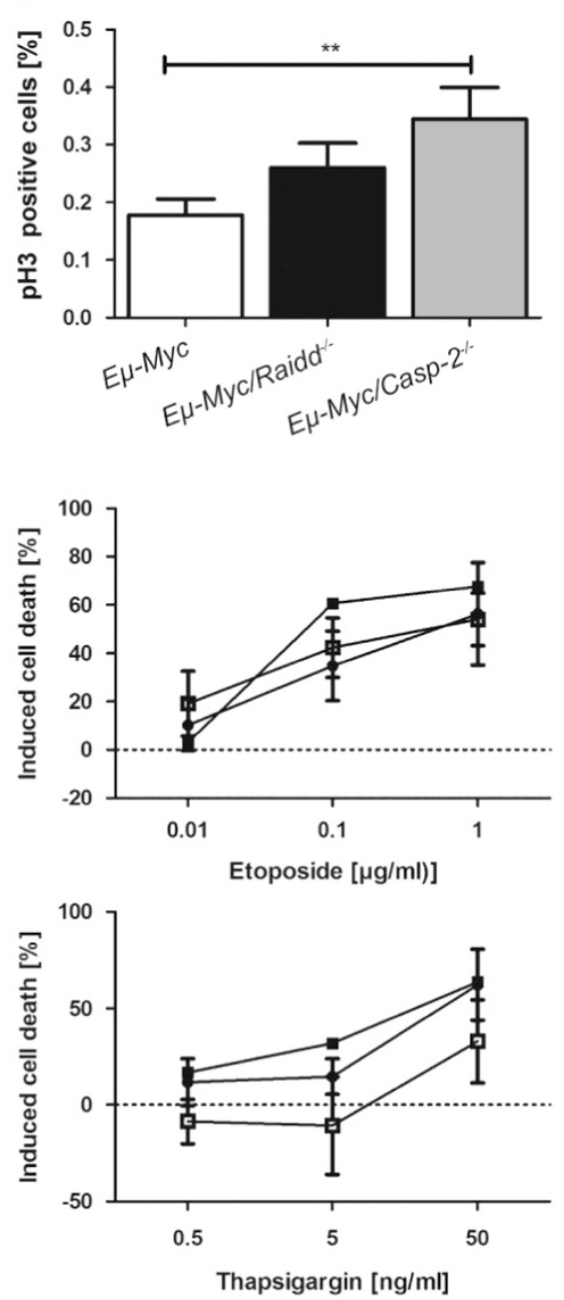
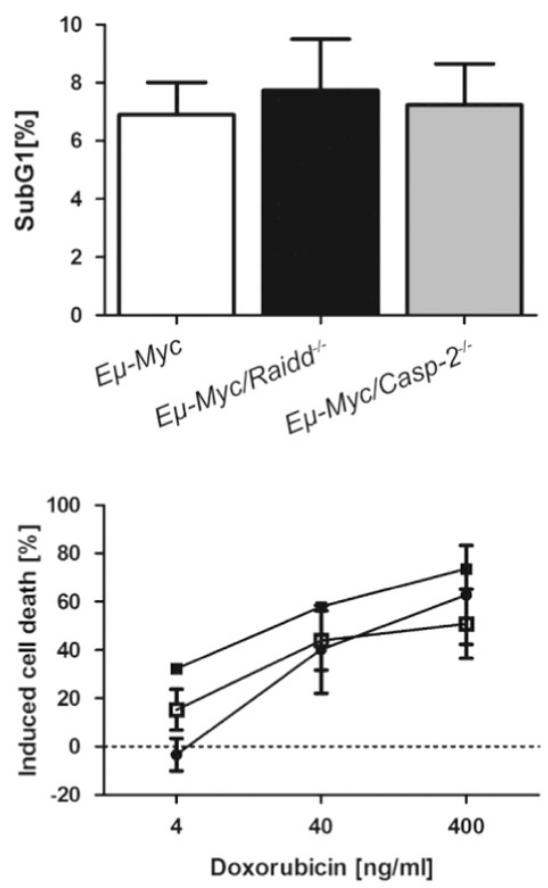

Figure 4 Normal cell cycle distribution and tumor cell apoptosis in E $\mu$-Myc tumor cells lacking Raidd. (a) Cell cycle phases G1 (black), S (dotted) and G2/M (white) of lymphoma cells were assessed ex vivo by intracellular DNA content analysis in tumors derived from $E \mu$-Myc $(n=21), E \mu-M y c / R^{\prime}$ idd ${ }^{\prime /-}(n=22), E \mu-M y c / C a s p-2^{-1-}(n=10)$ mice. (b) To define the percentage of cells in M-phase, ex vivo tumor cells were stained with an antibody specific for the phosphorylated variant of Histone H3 (pH3) and propidium iodide. Bars represent mean values of pH3 ${ }^{+}$cells \pm S.E.M. E $\mu-M y c(n=17), E \mu-M y c / R_{\text {Raidd }}{ }^{-1}(n=11) E \mu-M y c / C a s p-2^{-1-}(n=5)$. (c) Apoptosis in situ was assessed by SubG1 analysis of freshly isolated lymph node tumor masses followed flow cytometric analysis (wt $n=24$, Raidd ${ }^{1-} n=22$, Casp-2 ${ }^{-1} n=10$ ) mean values \pm S.E.M. (d) Freshly isolated lymphoma cells were cultivated on feeder cells for $24 \mathrm{~h}$ and were either left untreated (upper left graph) or exposed to increasing doses of the indicated chemotherapeutics. Cell death was assessed by Annexin-V/7-AAD staining combined with anti-CD19 to identify $B$ cells. Symbols represent mean values, $n>3-7$ for each genotype \pm S.E.M.

and exclude a role of any of the PIDDosome components in these DNA-damage-driven models of cancer.

Strikingly, Raidd deficiency also had no influence on tumor latency in c-Myc-driven B-cell lymphomas (Figure 3a), contrasting the findings with Caspase-2- or Pidd1-deficient mice, where Caspase-2 acts as a tumor suppressor and Pidd1 as a tumor promoter in this model. Our data show that loss of Raidd is dispensable for the development of B-cell lymphomas in the $E \mu-M y c$ mouse model and that Raidd deficiency has no impact on the development, proliferation and cell death of premalignant and transformed cells (Figure 2). The results thus indicate that Caspase-2-mediated tumor suppression is independent of both Pidd1 and Raidd. This is in line with the idea that Caspase-2 autoactivation can occur without the need for additional accessory proteins. ${ }^{14-16}$ Consistent with our conclusion, it has been shown that Caspase-2 indeed appears to be able to exert biological effects that do not depend on either catalytic activity or interaction with RAIDD or PIDD1, exemplified by translational control of $\mathrm{p} 21$ levels. ${ }^{41}$ As reduced levels of p21 by Caspase-2 knockdown sensitizes Hct116 colon cancer cells to irradiation-induced cell death, ${ }^{41}$ one may speculate that a similar effect may account for the tumorsuppressive effect noted in E $\mu-M y c / C a s p-2^{-/}$mice. However, deficiency in Cdkn1a, encoding for p21, has no impact on the tumor latency in $E \mu-M y c$ mice, ${ }^{42}$ excluding this possibility. However, it remains possible that not all aspects of Caspase-2 biology are conserved between mice and humans, as previously also recognized for the Caspase-2-dependent Chk1-suppressed cell death pathway that appears functional in human cancer cells but not in mouse lymphocytes or MEF. ${ }^{43}$

It is also not easy to reconcile the findings connecting deregulated expression of RAIDD in human cancer 
a
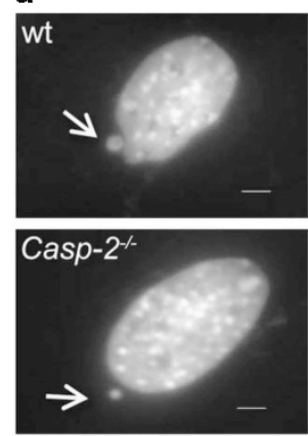

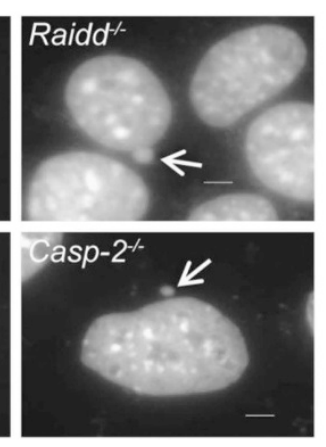

b

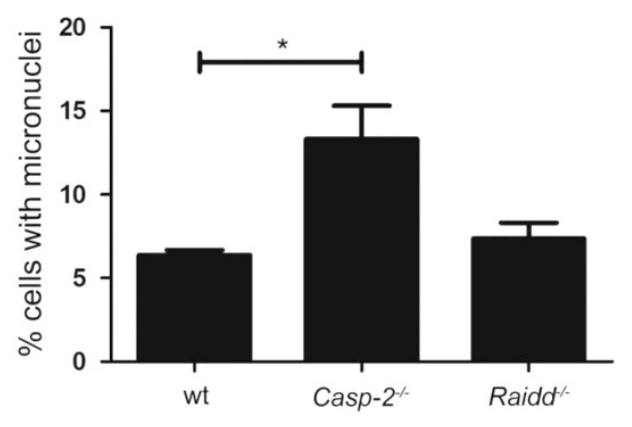

c
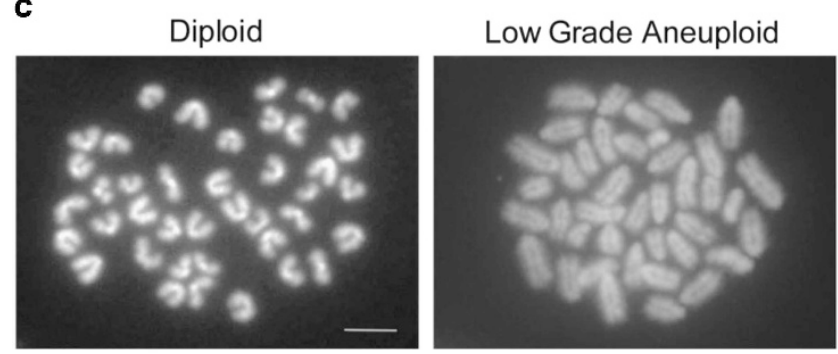

High Grade Aneuploid

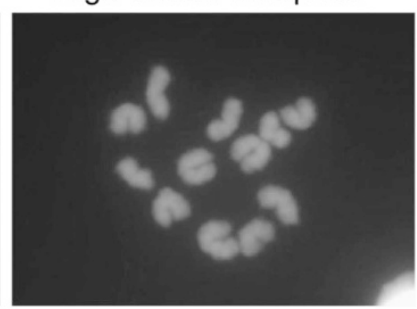

d

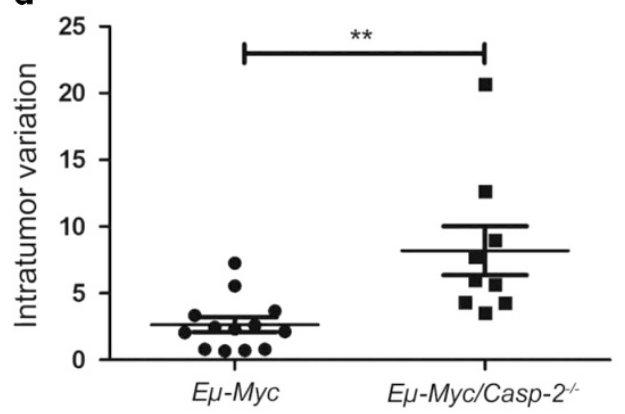

e

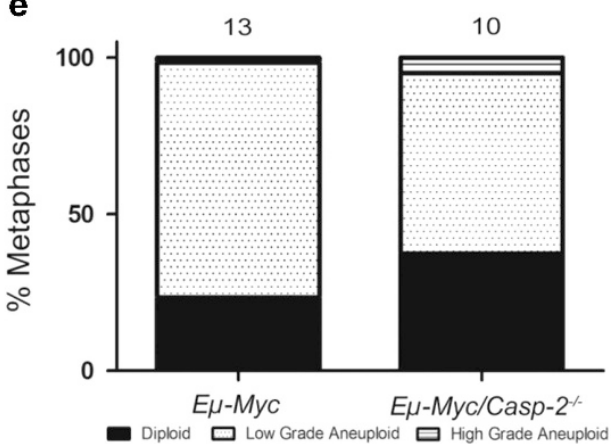

Figure 5 Caspase-2-loss leads to increased micronuclei formation and aneuploidy. (a) Representative images of micronuclei formation in SV40 MEFs of the indicated genotypes stained with $4^{\prime}, 6^{\prime}$-diamidino-phenylinodole. Arrows indicate micronuclei formation in wt MEFs. Scale bars $=5 \mu \mathrm{m}$. (b) Quantification of data assessed in a. A minimum of 300 cells per genotype was evaluated. Wt versus Casp- $2^{-1-}(P=0.03$; Student's $t$-test). Bars represent mean of $n>4-6$ for each genotype \pm S.E.M. (c) Representative images of chromosome spreads using freshly isolated $E \mu$-Myc lymphoma cells. Metaphase spreads are showing representative euploid (left panel) or aneuploidy karyogramms ranging from low (middle panel) to high-grade (right panel). Scale bar $=5 \mu \mathrm{m}$. A minimum of 50 spreads per genotype was evaluated. (d) Variation of counted chromosome numbers within single tumors from E $\mu$-Myc $(n=13)$ versus $E \mu-M y c / C a s p-2^{-1-}(n=10)$ mice $(P=0.0029$; Student's $t$-test). (e) Quantification of the variance of chromosome numbers in tumors derived from indicated genotypes. $\mathrm{A} \chi^{2}$ test showed a significant difference between wt and Casp-2 $-1-(P<0.0001)$

development and drug-resistant phenotypes ${ }^{10,25-27}$ with our data presented here. Although deregulated expression of RAIDD levels in cancer may be a bystander effect, for example, due to de-differentiation of cancer cells or deregulation of multiple signaling pathways ultimately also impacting on RAIDD mRNA levels, the differences in drug resistance, or lack thereof (our study) may simply be due to cell type-specific differences, the oncogenic drivers or the triggers used. Investigating the role of PIDDosome components in other, preferentially, non-hematological tumor models will shed some light.

Prior work linked loss of Caspase-2 to chromosomal and genomic instability as a possible driver of accelerated transformation. ${ }^{37}$ Consistently, SV40 MEFs and c-Myc transgenic B cells lacking Caspase-2 showed significantly higher levels of micronuclei formation and numbers of chromosomes in metaphase spreads diverted more strongly from the normal number. However, our analysis of chromosome numbers in $E \mu-M y c$ B-cell tumors did not show a direct increase in the frequency of aneuploidy in cells lacking Caspase-2. Instead, we found that the aneuploid cells present in the Caspase-2deficient tumors showed a greater variation of chromosome numbers in the same tumor sample. Furthermore, our data show that the level of high-grade aneuploidy (i.e., a loss or gain of more than 10 chromosomes) was greater in Caspase-2-1tumors. Together, these results clearly support a possible role of Caspase-2 in maintaining genomic integrity, whereas loss of the adaptor protein Raidd is dispensable for genomic stability (not shown).

As it is difficult to connect these observations with known substrates of Caspase-2 and the analysis of representative p53-induced genes failed to support impaired murine double 
minute 2 activity, as reported in cisplatin-treated lung cancer cells, ${ }^{40}$ we performed whole transcriptome analysis on premalignant $E \mu-M y c$ pre-B cells lacking or expressing Caspase-2 (or Raidd). However, we again failed to identify possible candidates that may be involved in the observed tumor-suppressor phenotype and established p53 targets were also not deregulated (Supplementary Figure 2). Hence, it remains possible that the phenomenon of reduced p53 activation in the absence of Caspase-2 is cell type-specific, for example, in lung epithelium, ${ }^{40}$ and/or a particular secondary hit, or a fully transformed cellular state. ${ }^{37}$ Consistent with the latter scenario, we previously reported on a reduced selective pressure to inactivate p53 in E$\mu$-Myc lymphomas lacking Caspase-2. ${ }^{4}$

In summary, our data suggest that Raidd does not influence the development of tumors after DNA-damage stress or the overexpression of oncogenes. This is in strong contrast to the opposing effects of its putative interaction partners, Caspase2 or Pidd1. ${ }^{3,4}$ Hence, the function of Raidd as a 'direct activator of Caspase-2' needs to be re-considered, at least in the context of E $\mu-M y c$-driven tumorigenesis and justifies the search for additional activators as well as substrates of Caspase-2 to understand its tumor-suppressive function at the molecular level.

\section{Materials and Methods}

Mice. All animal experiments were performed in accordance to the Austrian legislation (BGBI. Nr. 501/1988 i.d.F. 162/2005, \# BMWF-66.011/0137-II/10b/2009). The generation and genotyping of Casp- $2^{-1-}$, Raidd ${ }^{\prime-}, p 53^{+/-}$and $E \mu-M y c$ transgenic mice have been described elsewhere. ${ }^{34,44-46}$ All mice used for the experiments were on an inbred $\mathrm{C} 57 \mathrm{BL} / 6$ background.

Tumorigenesis induced by DNA damage. To induce thymic lymphomas, mice at the age of 4 weeks irradiated with $1.75 \mathrm{~Gy}$ in a linear accelerator once per week for 4 weeks. Muscular sarcoma formation was induced by a single $200 \mu \mathrm{l}$ intra muscular injection of $1 \mathrm{mg}$ 3-MC per mouse (Sigma, Vienna, Austria), dissolved in sesame oil. Mice treated with sesame oil alone (vehicle) served as a control.

Cell culture and reagents. Primary tumor cells derived from $E \mu-M y c$, $E \mu$-Myc/Raidd ${ }^{/-}$, E $\mu$-Myc/Casp-2 ${ }^{-1-}$ and $E \mu-M y c / P i d d 1^{-1-}$ mice were cultured in DMEM (PAA, GE Healthcare, Pasching, Austria), supplemented with 10\% FCS (PAA) Pen/Strep (Sigma), $250 \mu \mathrm{M}$ L-Glutamine (Gibco/Invitrogen, Vienna, Austria) and $50 \mu \mathrm{M}$ 2-mercaptoethanol (Sigma) and were kept on irradiated Bcl-2overexpressing $\mathrm{NIH}-3 \mathrm{~T} 3$ feeder cells. Tested agents and concentrations were: Etoposide $(0.01-1 \mathrm{mg} / \mathrm{ml})$, Dexamethasone $\left(10^{9}-10^{7} \mathrm{M}\right)$, Paclitaxel $(0.5-50 \mathrm{mM})$, Thapsigargin $(0.5-50 \mathrm{ng} / \mathrm{ml})$ and Doxorubicin $(4-400 \mathrm{ng} / \mathrm{ml}$; all from Sigma). FACSsorted pre-B, immature and $\operatorname{lgM}^{+} B$ cells were cultured in DMEM with supplements and spontaneous cell death was monitored over time.

Flow cytometric analysis and cell sorting. Tumors were analyzed by flow cytometry using the following cell surface markers for (a) B cells: RA3-6B2, anti-B220; R2/60, anti-CD43; I//41, anti-IgM; 11/26C, anti-lgD; MB19-1, anti-CD19; 53-7.3, antiCD5 and B3B4, anti-CD23; 7E9, anti-CD21 (BioLegend, Fell, Germany); and (b) T cells: GK1.5, anti-CD4; H57-597, anti-TCRb (all from eBioscience, Vienna, Austria) and 53-6.7, anti-CD8; (from BD Pharmingen, San Diego, CA, USA). Biotinylated antibodies were monitored with streptavidin-RPE (DAKO, Vienna, Austria) or streptavidin-PE-Cy7 (BD Phamingen). Using a FACS Vantage cell sorter (Becton

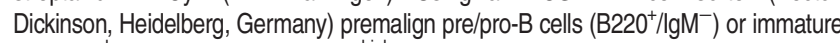
$\left(\mathrm{lgM}^{+} / \operatorname{lgD}{ }^{\text {low }}\right)$ and mature $\left(\mathrm{lgM}^{+} / \lg \mathrm{D}^{\text {high }}\right) \mathrm{B}$ cells were isolated and sorted from bone marrow and spleen, respectively. Flow cytometry data were analyzed using Cyflogic free ware and FlowJo (Ashland, OR, USA).

Immunoblotting. Proteins were extracted from tumor cells for $1 \mathrm{~h}$ on ice in protein lysis-buffer. ${ }^{36}$ Insoluble debris was cleared by centrifugation for $5 \mathrm{~min}$ at 13000 r.p.m. and $4{ }^{\circ} \mathrm{C}$. For evaluation of the p53 status of tumor cells $30 \mu \mathrm{g}$ protein/lane was separated by SDS-PAGE, transferred to a nitrocellulose membrane and probed with rat anti-p19/ARF (5-C3-1; Santa Cruz Biotechnology, SzaboScandic, Vienna, Austria) or mouse anti-p53 antiserum (1C12; Cell Signaling, New England Biolabs, Frankfurt, Germany). Comparability of protein loading was assessed by re-probing membranes with an antibody recognizing GAPDH (Sigma). Horseradish peroxidase-conjugated sheep anti-rat Ig antibodies (Jackson Research, Vienna, Austria), goat anti-rabbit or rabbit anti-mouse antibodies (DAKO) were used as secondary antigens. Antibody binding was detected using enhanced chemiluminiscence (Amersham, Freiburg, Germany) system.

Cell cycle analysis. Cell cycle analysis was based on fixing lymphoma cells in $70 \%$ ethanol and staining with PI (propidium iodide at $40 \mu \mathrm{g} / \mathrm{ml}$; Sigma). To analyze the percentage of cells in M-phase, ethanol-fixed lymphoma cells were permeabilized using Triton-X $(0.25 \%$, Sigma $)$ for $15 \mathrm{~min}$ on ice and co-stained with phosphorylated H3 (Ser10; Cell Signaling) and PI. Distribution of cell cycle phases was analyzed using a FACScan cell cytometer (BD, Heidelberg, Germany).

BrdU incorporation. Cell proliferation of immature $\left(\mathrm{CD} 19^{+} \operatorname{lgM}{ }^{-}\right)$and mature $\left(\mathrm{CD}^{+} 9^{+} \mathrm{gM}^{+}\right) \mathrm{B}$ cells in premalignant 4-week-old mice was assessed by injecting $1 \mathrm{mg} \mathrm{BrdU/mouse} \mathrm{i.p.} \mathrm{Four} \mathrm{hours} \mathrm{later,} \mathrm{primary} \mathrm{cells} \mathrm{derived} \mathrm{from} \mathrm{bone} \mathrm{marrow} \mathrm{and}$ spleen were isolated and stained for BrdU incorporation using the BrdU/APC flow kit (BD, Vienna, Austria) according to the manufacturer's recommendation. Samples were analyzed using FACS-Calibur (BD).

Cell viability assay. Tumor cells were co-stained with Annexin-V-FITC (1:1800 in Annexin-V-binding buffer; BD) and 7-AAD (1 $\mu \mathrm{g} / \mathrm{ml}$, Sigma) and spontaneous cell death was analyzed by subsequent flow cytometric analysis.

Cytogenetic analysis. Micronuclei were examined by seeding $2 \times 10^{5} \mathrm{MEF}$ on a sterile coverslip treated with cytochalasin $(4 \mu \mathrm{g} / \mathrm{ml})$ for $16 \mathrm{~h}$ before fixation in PTEMF fixative ${ }^{47}$ for $10 \mathrm{~min}$ and staining with $4^{\prime}, 6^{\prime}$-diamidino-phenylinodole. A minimum of 300 cells per condition and genotype were screened for micronuclei under a ZEISS IMAGER Z1 Microscope and Zeiss EC Plan-NEOFLUAR 40×/0,75 Ph2 objective using AxioVision Release 4.8.2 imaging software (Zeiss, Oberkochen, Germany).

Chromosome spreads from freshly isolated tumors were generated by incubating $1 \times 10^{6}$ lymphoma cells in media containing $1 \mu \mathrm{M}$ nocodazole (Sigma) for $5 \mathrm{~h}$ at $37^{\circ} \mathrm{C}$ in a $\mathrm{CO}_{2}$ incubator. After collecting and washing the cells in PBS, the pellet was resuspended in $5 \mathrm{ml} 0.075 \mathrm{M} \mathrm{KCl}$ (Merck) and incubated for $5 \mathrm{~min}$ at $37^{\circ} \mathrm{C}$. Then $1 \mathrm{ml}$ Carnoys fixative (Methanol:Acetic Acid $=3: 1$ ) was added. Cells were spun down (1200 $\mathrm{g}$ for $3 \mathrm{~min}$ ) and fixed in $1 \mathrm{ml}$ Carnoys fixative (repeated three times). Cells were added drop-wise (from $\sim 50 \mathrm{~cm}$ hight) onto a coverslip, air dried and stained with $4^{\prime}, 6^{\prime}$-diamidino-phenylinodole. A minimum of 50 chromosome spreads per tumor sample was analyzed at $\times 100$ magnification.

qRT-PCR analysis. RNA was isolated using TRIzol (Invitrogen) and transcribed into cDNA (Omniscript, Qiagen, Hilden, Germany) using random hexamer primers after DNAse digestion (Promega, Mannheim, Germany). cDNA of interest was amplified using primers listed in Supplementary Table 1 and $2 \times$ DyNAmo Color Flash SYBR Green Master Mix (Thermo Scientific, Vienna, Austria) in an Eppendorf Mastercycler ep realplex ${ }^{2}$ cycler. Relative expression of target/housekeeper was calculated using the delta-CT method.

Microarray data set generation and analysis. Microarray data for gene expression were obtained using Affymetrix MoGene 1.0 ST v.1 arrays (Affymetrix, Santa Clara, CA, USA). Sample preparation was performed according to the manufacturer's protocol. In brief, $250 \mathrm{ng}$ of high-quality RNA per sample were processed using the Ambion Affymetrix GeneChip WT Expression Kit (Part no. 308 4411974, Ambion/Thermo Scientific, Vienna, Austria) and the Affymetrix GeneChip WT Terminal Labeling Kit (Affymetrix). The resulting biotinylated targets were hybridized in an Affymetrix hybridization oven to a total of 14 Affymetrix MoGene 1.0 ST v.1 microarrays, which were then washed and stained in an Affymetrix fluidic station 450. Raw fluorescence signals were recorded in an Affymetrix scanner 3000 and image analysis was made with the Affymetrix GeneChip Command Console software.

Subsequent analyses have been performed in $\mathrm{R}$ (version 3.0.2) using packages from the Bioconductor project ${ }^{48}$ (version 2.13, BioConductor project: Fred Hutchinson Cancer Research Center, Seattle, WA, USA). The raw microarray data were preprocessed using 'generalgcrma' package ${ }^{49}$ and our custom transcript-level 'CEL definition file' (CDF) as described in Bindreither et al..$^{50}$ Transcripts for all genes have 
been defined using Ensembl version 71 (EMBL-EBI, Wellcome Trust Genome Campus, Hinxton, UK). The CDF contained a total of 63455 probe sets for 22991 genes. Background adjustment, normalization and summarization of the microarray data were performed using the GCRMA method. ${ }^{51}$ Further, a single-probe set per gene was selected as following: (a) if there were probe sets with more than 5 probes, only those were considered for further analysis, (b) if any of considered probe sets represented protein coding transcripts, the list of probe sets was limited to such and (c) the probe set which had the highest multiple of average expression and standard deviation across all samples was chosen for expression analysis.

Differential expression analysis was performed using limma package. ${ }^{52} P$-values were adjusted for multiple hypotheses testing correction by method of Benjamini and Hochberg. ${ }^{53}$ Genes with adjusted $P$-value $<0.05$ and absolute log2 fold change $>1$ were considered to be significantly regulated.

The raw and pre-processed microarray data have been submitted to the Gene Expression Omnibus (accession number GSE64920).

Statistical analysis. Statistical analysis was performed using unpaired Student's t-test or ANOVA with Student-Newman-Keuls as post hoc test. Comparison of Kaplan-Meier survival plots was performed using a log-rank test and for evaluation of statistical difference in frequency distributions the $\chi^{2}$ (Fisher's exact) analysis algorithm was used. $P$-values of $<0.05\left(^{*}\right)$ or $P<0.001\left(^{* *}\right)$ indicate significant differences.

\section{Conflict of Interest}

The authors declare no conflict of interest.

Acknowledgements. We thank I. Gaggl and C. Soratroi for excellent technical assistance as well as K. Rossi and B. Rieder for animal care. We further thank Professor P. Lukas and his team (LINAC 1-4), Department of Therapeutic Radiology and Oncology, Medical University Innsbruck, for enabling irradiation experiments, R. Kofler for help with gene-chip analysis and G. Böck for cell sorting. L. Peintner was supported by a DOC Fellowship of the Austrian Academy of Sciences (ÖAW). This study was funded by the 'Österreichische Krebshilfe', Branch Tyrol; the Austrian Science Fund (Project P 26856) and the MCBO postgraduate program (Project: W1101) as well as the National Health and Medical Research Council grants (1002863 and 1043057).

1. Mcllwain DR, Berger T, Mak TW. Caspase functions in cell death and disease. Cold Spring Harbor Perspect Biol 2013; 5: 4.

2. Puccini J, Dorstyn L, Kumar S. Caspase-2 as a tumour suppressor. Cell Death Differ 2013; 20: 1133-1139.

3. Ho LH, Taylor R, Dorstyn L, Cakouros D, Bouillet P, Kumar S. A tumor suppressor function for caspase-2. Proc Natl Acad Sci USA 2009; 106: 5336-5341.

4. Manzl C, Peintner L, Krumschnabel G, Bock F, Labi V, Drach M et al. PIDDosomeindependent tumor suppression by Caspase-2. Cell Death Differ 2012; 19: 1722-1732.

5. Parsons MJ, McCormick L, Janke L, Howard A, Bouchier-Hayes L, Green DR. Genetic deletion of caspase-2 accelerates MMTV/c-neu-driven mammary carcinogenesis in mice. Cell Death Differ 2013; 20: 1174-1182.

6. Puccini J, Shalini S, Voss AK, Gatei M, Wilson CH, Hiwase DK et al. Loss of caspase-2 augments lymphomagenesis and enhances genomic instability in Atm-deficient mice. Proc Natl Acad Sci USA 2013; 110: 19920-19925.

7. Terry MR, Arya R, Mukhopadhyay A, Berrett KC, Clair PM, Witt B et al. Caspase-2 impacts lung tumorigenesis and chemotherapy response in vivo. Cell Death Differ 2015; 22: 719-730.

8. Kumar S, White D, Takai S, Tuczynowicz S, Juttner C, Hughes T. Apoptosis regulatory gene NEDD2 maps to human chromosome segment $7 \mathrm{q} 34-35$, a region fequently affected in haematological neoplasms. Hum Genet 1995; 95: 641-644.

9. Estrov Z, Thall PF, Talpaz M, Estey EH, Kantarjian HM, Andreeff M et al. Caspase 2 and Caspase 3 protein levels as predictors of survival in acute myelogenous leukemia. Blood 1998; 92: 3090-3097.

10. Hofmann WK, de Vos S, Tsukasaki K, Wachsman W, Pinkus G, Said J et al. Altered apoptosis pathways in mantle cell lymphoma detected by oligonucleotide microarray. Blood 2001; 98: 787-794.

11. Holleman A, MLd Boer, Kazemier KM, Beverloo HB, von Bergh ARM, Janka-Schaub GE et al. Decreased PARP and procaspase-2 protein levels are associated with cellular drug resistance in childhood acute lymphoblastic leukemia. Blood 2005; 106: 1817-1823.

12. Kim MS, Kim HS, Jeong EG, Soung YH, Yoo NJ, Lee SH. Somatic mutations of caspase-2 gene in gastric and colorectal cancers. Pathol Res Pract 2011; 207: 640-644.

13. Ren K, Lu J, Porollo A, Du C. Tumor-suppressing Function of Caspase-2 Requires Catalytic Site Cys-320 and Site Ser-139 in Mice. J Biol Chem 2012; 287: 14792-14802.
14. Colussi PA, Harvey NL, Kumar S. Prodomain-dependent Nuclear Localization of the Caspase-2 (Nedd2) Precursor: A NOVEL FUNCTION FOR A CASPASE PRODOMAIN. J Biol Chem 1998; 273: 24535-24542.

15. Butt AJ, Harvey NL, Parasivam G, Kumar S. Dimerization and Autoprocessing of the Nedd2 (Caspase-2) Precursor Requires both the Prodomain and the Carboxyl-terminal Regions. J Biol Chem 1998; 273: 6763-6768.

16. Baliga BC, Read SH, Kumar S. The biochemical mechanism of caspase-2 activation. Cell Death Differ 2004; 11: 1234-1241.

17. Krumschnabel G, Sohm B, Bock F, Manzl C, Villunger A. The enigma of caspase-2: the laymen's view. Cell Death Differ 2009; 16: 195-207.

18. Krumschnabel G, Manzl C, Villunger A. Caspase-2: killer, savior and safeguard-emerging versatile roles for an ill-defined caspase. Oncogene 2009; 28: 3093-3096.

19. Tinel A, Tschopp J. The PIDDosome, a protein complex implicated in activation of caspase-2 in response to genotoxic stress. Science 2004; 304: 843-846.

20. Bock FJ, Peintner L, Tanzer M, Manzl C, Villunger A. P53-induced protein with a death domain (PIDD): master of puppets. Oncogene 2012; 31: 4733-4739.

21. Duan H, Dixit V. RAIDD is a new 'death' adaptor molecule. Nature 1997; 238: 86-89.

22. Zhou P, Chou J, Olea R, Yuan J, Wagner G. Solution structure of Apaf-1 CARD and its interaction with caspase-9 CARD-a structural basis for specific adaptor-caspase interaction. Proc Natl Acad Sci USA 1999; 96: 11265-11270.

23. Lin Q, Liu Y, Moore DJ, Elizer SK, Veach RA, Hawiger J et al. Cutting edge: the 'death' adaptor CRADD/RAIDD targets BCL10 and suppresses agonist-induced cytokine expression in T lymphocytes. J Immunol 2012; 188: 2493-2497.

24. Qiao H, Liu Y, Veach RA, Wylezinski L, Hawiger J. The Adaptor CRADD/RAIDD Controls Activation of Endothelial Cells by Proinflammatory Stimuli. J Biol Chem 2014; 289: 21973-21983.

25. Yang C, Hornicek FJ, Wood KB, Schwab JH, Mankin H, Duan Z. RAIDD expression is impaired in multidrug resistant osteosarcoma cell lines. Cancer Chemother Pharmacol 2009; 64: 607-614.

26. Hasegawa H, Yamada Y, Tsukasaki K, Mori N, Tsuruda K, Sasaki D et al. LBH589, a deacetylase inhibitor, induces apoptosis in adult T-cell leukemia/lymphoma cells via activation of a novel RAIDD-caspase-2 pathway. Leukemia 2011; 25: 575-587.

27. Mahoney D, Lefebvre C, Allan K, Brun J, Sanaei C, Baird S et al. Virus-tumor interactome screen reveals ER stress response can reprogram resistant cancers for oncolytic virustriggered Caspase-2 cell death. Cancer Cell 2011; 20: 443-456.

28. Janssens S, Tinel A, Lippens S, Tschopp J. PIDD mediates NF-kappaB activation in response to DNA damage. Cell 2005; 123: 1079-1092.

29. Matheu A, Maraver A, Klatt P, Flores I, Garcia-Cao I, Borras C et al. Delayed ageing through damage protection by the Art/p53 pathway. Nature 2007; 448: 375-379.

30. Harris AW, Pinkert CA, Crawford M, Langdon WY, Brinster RL, Adams JM. The E mu-myc transgenic mouse. A model for high-incidence spontaneous lymphoma and leukemia of early B cells. J Exp Med 1988; 167: 353-371.

31. Michalak EM, Jansen ES, Happo L, Cragg MS, Tai L, Smyth GK et al. Puma and to a lesser extent Noxa are suppressors of Myc-induced lymphomagenesis. Cell Death Differ 2009; 16: 684-696.

32. Frenzel A, Labi V, Chmelewskij W, Ploner C, Geley S, Fiegl H et al. Suppression of B-cell lymphomagenesis by the BH3-only proteins Bmf and Bad. Blood 2010; 115: 995-1005.

33. Sochalska M, Tuzlak S, Egle A, Villunger A. Lessons from gain- and loss-of-function models of pro-survival Bcl2 family proteins: implications for targeted therapy. FEBS J 2015; 282 : 834-849.

34. Adams J, Harris A, Pinkert C, Corcoran L, Alexander W, Cory S et al. The c-myc oncogene driven by immunoglobulin enhancers induces lymphoid malignancy in transgenic mice. Nature 1985; 318: 533-538

35. Egle A, Harris AW, Bouillet P, Cory S. Bim is a suppressor of Myc-induced mouse B cell leukemia. Proc Natl Acad Sci USA 2004; 101: 6164-6169.

36. Eischen CM, Weber JD, Roussel MF, Sherr CJ, Cleveland JL. Disruption of the ARF-Mdm2p53 tumor suppressor pathway in Myc-induced lymphomagenesis. Genes Dev 1999; 13: 2658-2669.

37. Dorstyn L, Puccini J, Wilson CH, Shalini S, Nicola M, Moore S et al. Caspase-2 deficiency promotes aberrant DNA-damage response and genetic instability. Cell Death Differ 2012; 19: 1288-1298.

38. Fava LL, Bock FJ, Geley S, Villunger A. Caspase-2 at a glance. J Cell Sci 2012; 125: 5911-5915.

39. Bric A, Miething C, Bialucha CU, Scuoppo C, Zender L, Krasnitz A et al. Functional identification of tumor suppressor genes through an in vivo RNA interference screen in a mouse lymphoma model. Cancer Cell 2009; 16: 324-335.

40. Oliver TG, Meylan E, Chang GP, Xue W, Burke JR, Humpton TJ et al. Caspase-2-mediated cleavage of Mdm2 creates a p53-induced positive feedback loop. Mol Cell 2011; 43: 57-71.

41. Sohn D, Budach W, Janicke RU. Caspase-2 is required for DNA damage-induced expression of the CDK inhibitor p21(WAF1/CIP1). Cell Death Differ 2011; 18: 1664-1674.

42. Newbold A, Salmon JM, Martin BP, Stanley K, Johnstone RW. The role of p21waf1/cip1 and p27Kip1 in HDACi-mediated tumor cell death and cell cycle arrest in the E $\mu$-myc model of B-cell lymphoma. Oncogene 2014; 33: 5415-5423.

43. Manzl C, Fava LL, Krumschnabel G, Peintner L, Tanzer MC, Soratroi C et al. Death of p53defective cells triggered by forced mitotic entry in the presence of DNA damage is not uniquely dependent on Caspase-2 or the PIDDosome. Cell Death Dis 2013; 4: e942.

44. O'Reilly L, Ekert P, Harvey N, Mardsen V, Cullen L, Vaux D et al. Caspase-2 is not required for thymocyte or neuronal apoptosis even though cleavage of caspase-2 is dependent on both Apaf-1 and caspase-9. Cell Death Differ 2002; 9: 832-841. 
45. Berube C, Boucher LM, Ma W, Wakeham A, Salmena L, Hakem R et al. Apoptosis caused by p53-induced protein with death domain (PIDD) depends on the death adapter protein RAIDD. Proc Natl Acad Sci USA 2005; 102: 14314-14320.

46. Garcia-Cao I, Garcia-Cao M, Martin-Caballero J, Cridao LM, Klatt P, Flores JM et al. 'Super p53' mice exhibit enhanced DNA damage response, are tumor resistant and age normally. EMBO J 2002; 21: 6225-6235.

47. Elowe S, Dulla K, Uldschmid A, Li X, Dou Z, Nigg EA. Uncoupling of the spindle-checkpoint and chromosome-congression functions of BubR1. J Cell Sci 2010; 123: 84-94.

48. Gentleman R, Carey V, Bates D, Bolstad B, Dettling M, Dudoit S et al. Bioconductor: open software development for computational biology and bioinformatics. Genome Biol 2004; 5: R80.

49. Rainer J, Lelong J, Bindreither D, Mantinger C, Ploner C, Geley S et al. Research resource: transcriptional response to glucocorticoids in childhood acute lymphoblastic leukemia. $\mathrm{Mol}$ Endocrinol 2012; 26: 178-193.

50. Bindreither D, Ecker S, Gschirr B, Kofler A, Kofler R, Rainer J. The synthetic glucocorticoids prednisolone and dexamethasone regulate the same genes in acute lymphoblastic leukemia cells. BMC Genomics 2014; 15: 662.

51. Wu Z, Irizarry RA, Gentleman R, Martinez-Murillo F, Spencer F. A model-based background adjustment for oligonucleotide expression arrays. J Am Stat Association 2004; 99: 909-917.
52. Smyth GK. Linear models and empirical Bayes methods for assessing differential expression in microarray experiments. Stat Appl Genet Mol Biol 2004; 3: 29.

53. Benjamini $Y$, Hochberg $Y$. Controlling the false discovery rate: a practical and powerful approach to multiple testing. J $R$ Stat Soc Series B (Methodol) 1995; 57: 289-300.

(c) This work is licensed under a Creative Commons Attribution 4.0 International License. The images or other third party material in this article are included in the article's Creative Commons license, unless indicated otherwise in the credit line; if the material is not included under the Creative Commons license, users will need to obtain permission from the license holder to reproduce the material. To view a copy of this license, visit http:// creativecommons.org/licenses/by/4.0/

Supplementary Information accompanies this paper on Cell Death and Differentiation website (http://www.nature.com/cdd) 